\title{
A Design Study of High Breeding Ratio Sodium Cooled Metal Fuel Core without Blanket Fuels*
}

\author{
Noboru KOBAYASHI**, Takashi OGAWA**, Shigeo OHKI**, \\ Tomoyasu MIZUNO** and Takanari OGATA*** \\ **Japan Atomic Energy Agency (JAEA) \\ 4002 Narita-cho, Oarai-machi, Ibaraki, Japan \\ E-mail:kobayashi.noboru@jaea.go.jp \\ *** Central Research Institute of Electric Power Industry (CRIEPI) \\ 2-11-1 Iwado kita, Komae-shi, Tokyo, Japan
}

\begin{abstract}
The metal fuel core is superior to the mixed oxide fuel core because of its high breeding ratio and compact core size resulting from hard neutron spectrum and high heavy metal densities. Utilizing these characteristics, a conceptual design for a high breeding ratio was performed without blanket fuels. The design conditions were set so a sodium void worth of less than $8 \$$, a core height of less than $150 \mathrm{~cm}$, the maximum cladding temperature of $650{ }^{\circ} \mathrm{C}$, and the maximum fuel pin bundle pressure drop of 0.4MPa. The breeding ratio of the resultant core was 1.34 with $6 \mathrm{wt} \%$ zirconium content fuel. Applying $3 \mathrm{wt} \%$ zirconium content fuel enhanced the breeding ratio up to 1.40 .
\end{abstract}

Key words: Sodium Cooled Fast Reactor, Metal Fuel Core, Breeding Ratio, Zr-Content, Bundle Pressure Drop, Sodium Void Worth, Nuclear Reactor, Nuclear Energy, Nuclear Engineering

\section{Introduction}

A sodium-cooled fast breeder reactor (SFR) core using metal fuel is one of the promising candidates for advanced SFR core concept, because it has several advantages to the mixed oxide fuel core, i.e., a small inventory and a high breeding ratio resulting from hard neutron spectrum and high heavy metal densities. On the contrary, the maximum cladding temperature with metal fuel is limited due to cladding compatibility concerns, which forces limitations upon the core outlet temperature.

In order to overcome the disadvantage, JAEA has carried out a conceptual metal fuel core design study ${ }^{(1)(2)}$ to achieve an identical core outlet coolant temperature with that of the mixed oxide fuel core as a part of the Fast reactor Cycle Technology development project $(\mathrm{FaCT})^{(3)}$. In the $\mathrm{FaCT}$ project, the conditions of the core design have been determined from the viewpoints of near-future feasibility of the fast breeder reactor systems, that is, they have been given from the practical fuel specifications based on the present irradiation test results, the plant design requirements, and the SFR deployment scenario in Japan.

However, the fuel specifications could be more flexible by accumulating irradiation test results in future, by considering other possible SFR deployment scenarios, and so on. Setting the design conditions more flexibly, it is expected that there may be many attractive concepts that characterize the merits of the metal fuel cores, such as high breeding ratio, small fuel-inventory, compact core size, low sodium void worth (hereinafter, void worth), 
high transmutation rate of the minor actinides (MA) and so on. For example of the conceptual high breeding ratio core designs, Riyas et al. reported the breeding ratio of 1.61 with the radial and axial blanket fuels ${ }^{(4)}$. The breeding ratio consisted of the internal conversion ratio of 1.12 and the external of 0.49 . Dubberley et al. reported a high internal conversion ratio of 1.05 and the breeding ratio of 1.22 with axial blanket fuels ${ }^{(5)}$. A conceptual high breeding ratio core design without blanket fuels may be as a basic concept for the higher breeding ratio core design with blanket fuels. It also has other interests, when compared with those concepts with blanket fuels, such as the simplification of pyrometallurgical reprocessing system.

In the present paper, we concentrate to study the conceptual high breeding ratio core design without blanket fuels by setting the design conditions flexibly. The present conceptual core design is aimed to specialize in high breeding ratio. The small fuel inventory, low void worth and high MA-transmutation core designs will be reported in future papers, and the merits and demerits among them will be discussed.

\section{Design Conditions}

The design conditions in the present study are shown in Table 1. The maximum core height was given from the viewpoint of protection from creep deformation under the fuel slug's own weight. The value was set as a tentative value based on the irradiation test results of $124.4 \mathrm{~cm}$-length fuel pins at $\mathrm{ANL}^{(6)}$. The outer diameter of the fuel pins was based on manufacturing and irradiation test results. The $\mathrm{Zr}$-content of the fuel was basically set at the same range as in the FaCT project, $6-10 \mathrm{wt} \%$. The $3 \mathrm{wt} \%$ zirconium

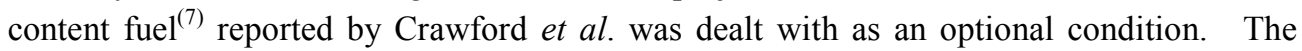
fuel transuranium (TRU) isotopic composition is based on the metal fuel fast reactor core equilibrium after the multi recycling of the metal fuel core.

Table 1 Current core design conditions

\begin{tabular}{|c|c|c|}
\hline \multicolumn{2}{|r|}{ Item } & Design conditions \\
\hline \multirow{2}{*}{$\begin{array}{l}\text { Plant } \\
\text { Spec. }\end{array}$} & Core thermal output & $3,530 \mathrm{MWt}$ \\
\hline & Core coolant flow rate & $18,000 \mathrm{~kg} / \mathrm{s}$ \\
\hline \multirow{6}{*}{$\begin{array}{l}\text { Advanced } \\
\text { Fuel Spec. }\end{array}$} & Fuel type & U-TRU-Zr alloy \\
\hline & Fuel TRU composition & Metal fuel FBR multi-recycle ${ }^{* 1}$ \\
\hline & Fuel pin outer diameter & $<8.5 \mathrm{~mm}$ \\
\hline & Fuel Zr-content & $3 \sim 14 \mathrm{wt} \%$ \\
\hline & Core height & $<150 \mathrm{~cm}$ \\
\hline & Spacer wire diameter & $>0.8 \mathrm{~mm}$ \\
\hline \multirow{8}{*}{$\begin{array}{l}\text { Flexible } \\
\text { Conditions }\end{array}$} & Breeding ratio & As high as possible \\
\hline & Core outlet/inlet temperature & Design output \\
\hline & Operation cycle length & Design output \\
\hline & Maximum fast neutron ${ }^{* 2}$ fluence & $5 \times 10^{23} \mathrm{n} / \mathrm{cm}^{2}$ \\
\hline & Void worth & $<8 \$$ \\
\hline & Bundle pressure drop & $<0.4 \mathrm{MPa}$ \\
\hline & Maximum cladding temperature & $<650^{\circ} \mathrm{C}$ \\
\hline & Cladding hoop stress & $<120 \mathrm{MPa}$ \\
\hline
\end{tabular}

In the present design, we consider thermal-hydraulic and fuel integrity conditions. The maximum fast neutron fluence and the maximum cladding temperature have been given as a target value of the ODS-steel claddings in the FaCT project. The core inlet and outlet temperatures were design outputs and allowed to be lower than those of the FaCT metal fuel core in order to satisfy the maximum cladding temperature. It is because the power swing 
is expected larger as the breeding ratio becomes large. As the fuel integrity conditions, cladding hoop stress was set less than $120 \mathrm{MPa}$, so the gas plenum length was given by taking into consideration of the inner pressure of the maximum burnup fuel pin.

In order to construct a design of the core consisting of the large fuel volume ratio subassemblies of long fuel pins, the bundle pressure drop condition was set as $0.4 \mathrm{MPa}$. It was determined from the roughly estimated value of the maximum bundle pressure drop of the prototype reactor MONJU. The bundle pressure drop was estimated by the MIT formula ${ }^{(8)}$. Flow rate of the peak power subassembly was estimated to satisfy the maximum cladding temperature.

The maximum void worth was given from the viewpoint of preventing the super-prompt criticality in the initiation phase of core disruptive accident caused by the unprotected loss of flow (ULOF) accident. The envelope diameter of shielding region and the operating cycle length were design outputs.

For convenience of discussion in the present study, Fig. 1 shows the configurations of the $\mathrm{FaCT}$ metal fuel core with high reactor outlet temperature. The core consists of 2-radial regions without blanket fuels and its breeding ratio is 1.03 . There are 150 and 495 subassemblies in the inner and the outer cores, respectively. The fuel $\mathrm{Zr}$-content of the inner core was $10 \mathrm{wt} \%$ and the outer core was $6 \mathrm{wt} \%$. The Pu-enrichment is common to both cores (hereinafter Pu-enrichment 1-region core). The core outlet temperature is 550 ${ }^{\circ} \mathrm{C}$, which was obtained by a reduction of the radial peaking factor, and by creating a stable power profile.

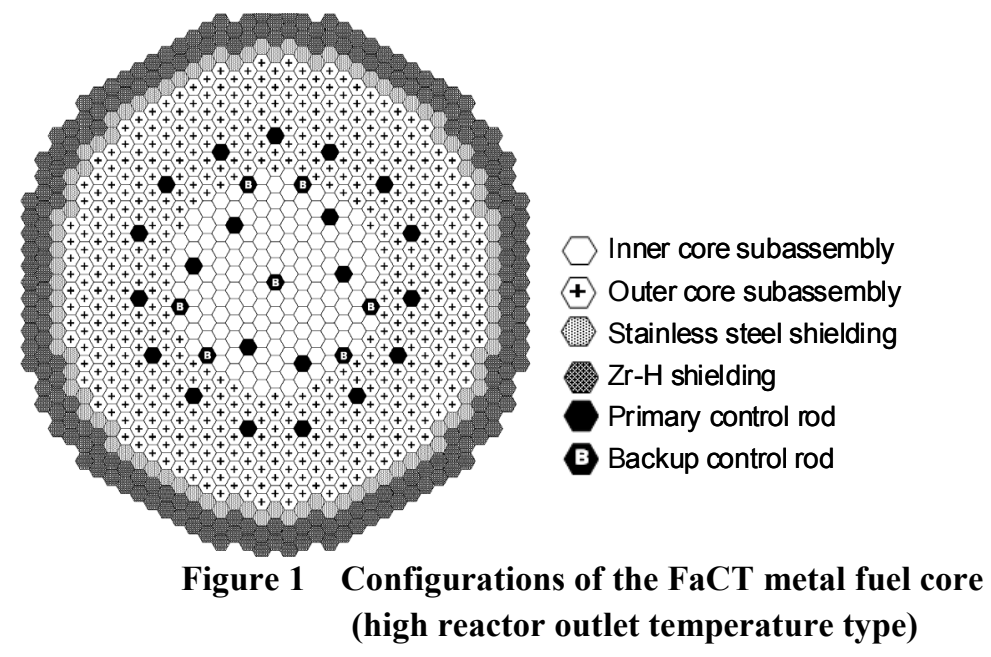

\section{Conceptual High Breeding Ratio Core Design}

\subsection{Tentative Core Design}

In order to obtain a high breeding ratio, the tentative core specifications were selected so that the neutron leakage is as small as possible. That is, a core height of $150 \mathrm{~cm}$ and a wire wrapped spacer diameter of $0.80 \mathrm{~mm}$ were selected. The Pu-enrichment and the operation cycle length were adjusted so that maximum of the fast neutron fluence was approximately $5 \times 10^{23} \mathrm{n} / \mathrm{cm}^{2}$ and that the minimum of the effective multiplication factor was not too small. All other specifications were the same as those for the FaCT core.

Table 2 shows major specifications and characteristics of the tentative and the $\mathrm{FaCT}$ cores. The breeding ratio of the tentative core was much larger than that of the FaCT core, 1.32 , without blanket fuels. The void worth was approximately $7.5 \$$, which satisfied the void worth condition. The operation cycle length was approximately 840 days, approximately 1.1 times longer than that of the $\mathrm{FaCT}$ core. The discharge burnup was 
approximately $54 \mathrm{GWd} / \mathrm{t}$. The radial peaking factor was 1.94 , which was approximately $50 \%$ larger than that of the FaCT core. This indicates that the radial power distribution was not flattened in the tentative core. With the exception of the bundle pressure drop, the tentative core design satisfied the conditions in Table 1. The pressure drop was $1.06 \mathrm{MPa}$. Therefore, for the construction of the conceptual high breeding ratio core design, it was found that the tentative core had to be adjusted so that the pressure drop would be less than $0.4 \mathrm{MPa}$.

Table 2 Major specifications and characteristics of tentative and FaCT cores

\begin{tabular}{|l|c|c|c|}
\hline \multicolumn{1}{|c|}{ Item } & Unit & Tentative core & FaCT metal fuel core \\
\hline Core height & $\mathrm{cm}$ & 150 & 75 \\
\hline Zr-content (Inner core/outer core) & $\mathrm{wt} \%$ & \multicolumn{2}{|c|}{$10.0 / 6.0$} \\
\hline Spacer wire diameter & $\mathrm{mm}$ & 0.80 & 1.00 \\
\hline Operation cycle length & days & 840 & 745 \\
\hline Pu-enrichment & $\mathrm{wt} \%$ & 8.7 & 12.2 \\
\hline Breeding ratio & - & 1.32 & 1.03 \\
\hline Discharge burnup & $\mathrm{GWd} / \mathrm{t}$ & 53.8 & 96.6 \\
\hline Pu-fissile inventory & $\mathrm{t} / \mathrm{GWe}$ & 6.8 & 4.7 \\
\hline Maximum linear heat rating & $\mathrm{W} / \mathrm{cm}$ & 259 & 347 \\
\hline Void worth & $\$$ & 7.52 & 6.15 \\
\hline Peak bundle power & $\mathrm{MW}$ & 10.6 & 7.3 \\
\hline Bundle pressure drop & $\mathrm{MPa}$ & 1.06 & 0.22 \\
\hline Core outlet temperature & ${ }^{\circ} \mathrm{C}$ & 532 & 550 \\
\hline
\end{tabular}

In order to reduce the bundle pressure drop under the condition of a $150 \mathrm{~cm}$-height core, we considered two manners; to reduce the peak fuel pin bundle power (hereinafter peak bundle power) and to enlarge the flow area. For reduction of the peak bundle power, we considered 1) applying the Pu-enrichment 2-region core, 2) adjusting the subassembly number ratio between the inner and outer cores, and 3) increasing subassembly number.

For the 2-region core, the $\mathrm{Zr}$-content of the fuels was set as $6 \mathrm{wt} \%$ in both the inner and the outer cores. It is because the lower $\mathrm{Zr}$-content fuel is preferred to obtain higher breeding ratio due to its higher heavy metal densities. The Pu-enrichment was determined so that the maximum linear heat rating of the inner core was nearly equal to that of the outer core. In Sec. 3.2, the better core type for the high breeding ratio core will be chosen between Pu-enrichment 1-resion core or the 2-resion one with the $\mathrm{Zr}$-contents of $6-10 \mathrm{wt} \%$. Application of the $3 \mathrm{wt} \% \mathrm{Zr}$-content fuel will be considered to the better core type.

\subsection{Effect of the Subassembly Number Ratio between Inner and Outer Cores}

The neutronic characteristics of the Pu-enrichment 1-region and 2-region cores were discussed with the subassembly number ratio between the inner and the outer cores parametrically changed. The results are shown in Fig. 2.

As the subassembly number ratio becomes larger, the breeding ratio decreases. Although the breeding ratio of the Pu-enrichment 1-region core is a slightly larger than the Pu-enrichment 2-region core, the difference is small.

The dependence of the void worth is, however, different between the 1-region and 2-region cores. For the 1-region core, the $\mathrm{Zr}$-content of the inner core is larger than that of the outer core. The core averaged zirconium content increases with the subassembly number ratio, and the void worth increases. On the other hand, for the 2-region core, the void worth is nearly constant because the core averaged zirconium content is independent of the subassembly number ratio. Therefore, the dependence of the void worth is different.

The discharge burnup of the Pu-enrichment 1-region core is less than $55 \mathrm{GWd} / \mathrm{t}$, although that of the 2-region core is approximately $70 \mathrm{GWd} / \mathrm{t}$. This indicates that the 
radial power distribution of the 2-region core is more flattened than that of the 1-region core, as shown in Fig. 3. In the 1-region core, the maximum power density in the inner core is $20 \%$ larger than that of the outer core. While in the 2-region core, the maximum power density in the inner core is nearly equal to that in the outer core.

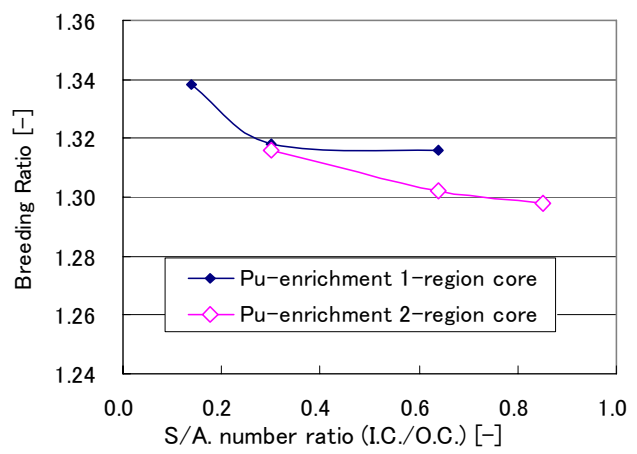

(a) Breeding ratio

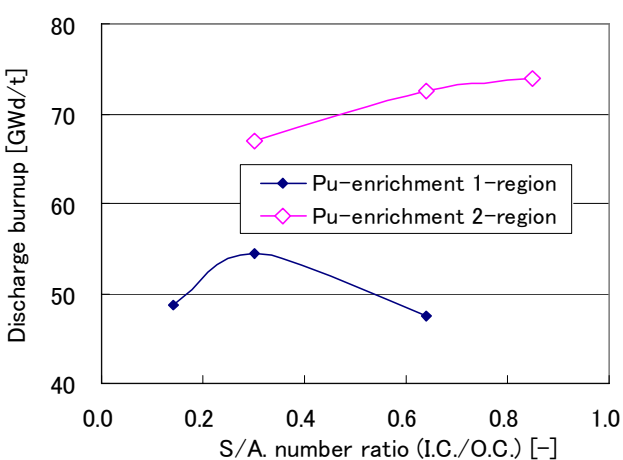

(c) Discharge burnup

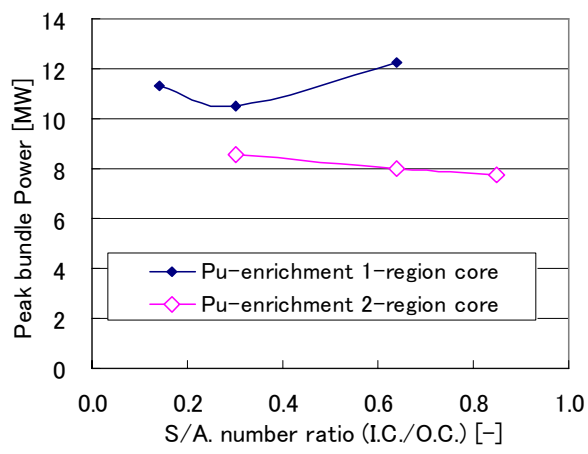

(e) Peak bundle power

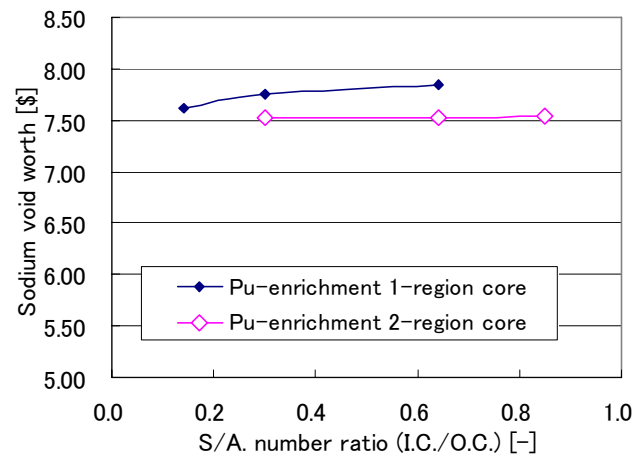

(b) Void worth

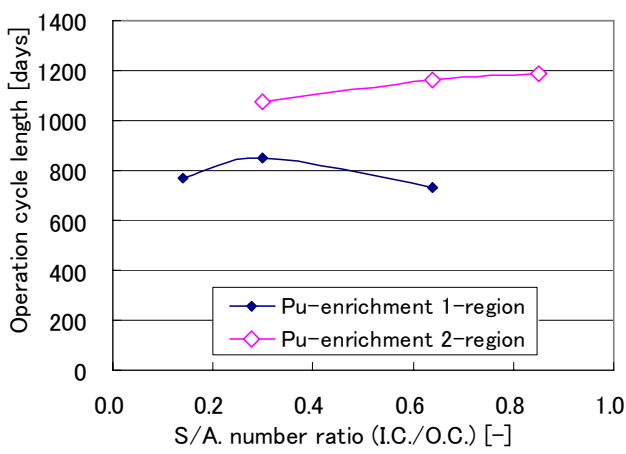

(d) Operation cycle length

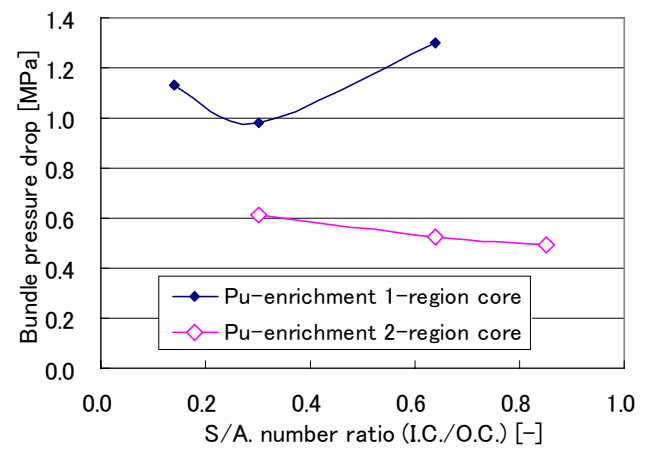

(f) Bundle pressure drop

Figure 2 Effect of subassembly number ratio upon core characteristics

(wire diameter $=0.85 \mathrm{~mm}$ )

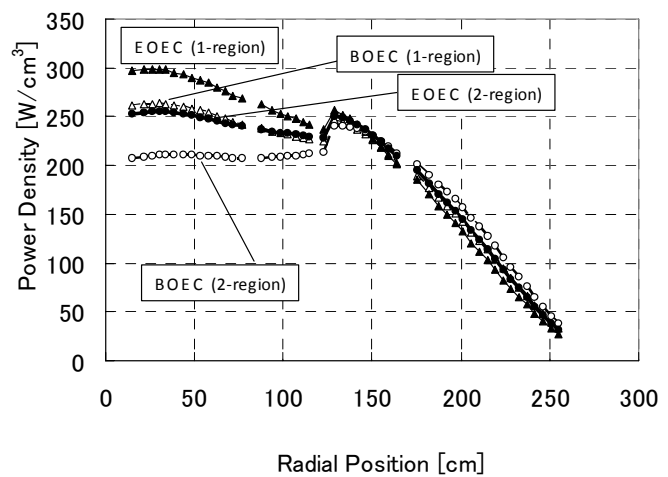

Figure 3 Radial distribution of power density 
The operation cycle length was set so that the maximum of the fast neutron fluence would be approximately $5 \times 10^{23} \mathrm{n} / \mathrm{cm}^{2}$. Because of the difference of the radial power distribution, the operation cycle length of the 2-region core is much longer than that of the 1-region core. The operation cycle length of the 1-region core takes the maximum of 850 days at a subassembly number ratio of 0.30 . That of the 2-region core is more than 1,000 days and it increased with the subassembly number ratio.

The bundle pressure drop of the 2-region core is smaller than that of the 1-region core. It is because the peak bundle power of the 2-region core is smaller. Although there were no results satisfying the bundle pressure drop condition, it was found that the Pu-enrichment 2-region core was more adopted for reduction of the peak bundle power and the bundle pressure drop than the Pu-enrichment 1-region core. Therefore, the Pu-enrichment 2-region core was selected for the conceptual high breeding ratio core design.

\subsection{Effect of Subassembly number and Wire Diameter}

As the subassembly number becomes larger, the peak bundle power and the bundle pressure drop decrease. Because the void worth increases with the subassembly number, the maximum wire diameter is reduced as the subassembly number becomes larger. Therefore, the wire diameter was also changed parametrically. The results are shown in Fig. 4. In the survey, the neutron fluencies and the core thermal output were fixed, so the power densities decrease as the subassembly number increases.

The breeding ratio increases slightly as the subassembly number becomes larger. For the 819 subassembly cores, the breeding ratio is approximately 1.33 , while for the 645 subassembly cores, it is approximately 1.31 .

The void worth increases with the subassembly number. The maximum wire diameter becomes smaller as the subassembly number increases. For the 645 subassembly core, the void worth condition was satisfied with $0.95 \mathrm{~mm}$-diameter wire, while for the 819 subassemblies core, the maximum value of the wire diameter was $0.90 \mathrm{~mm}$.

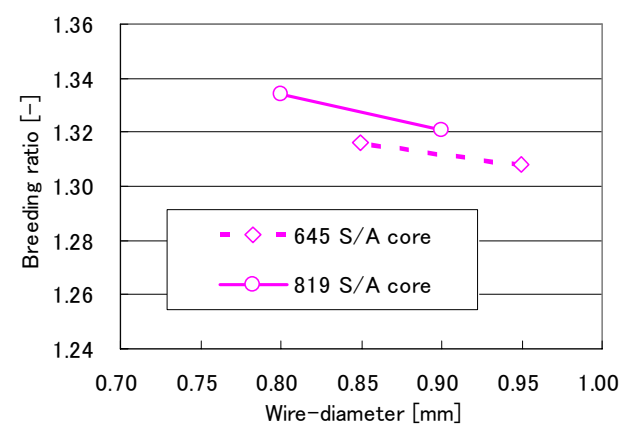

(a) Breeding ratio

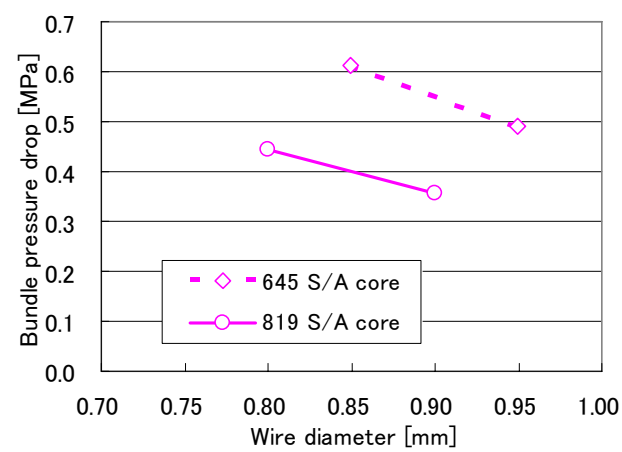

(c) Bundle pressure drop

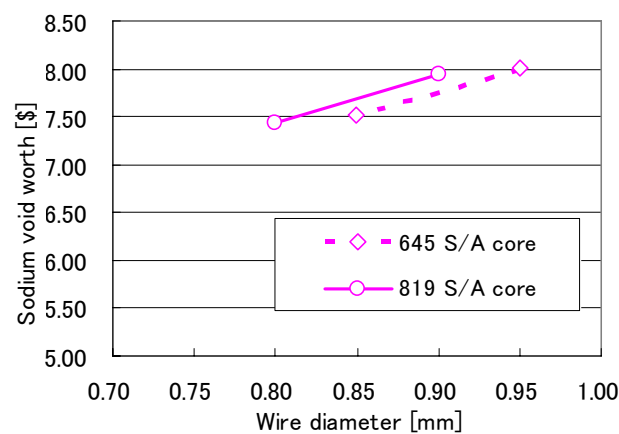

(b) Void worth

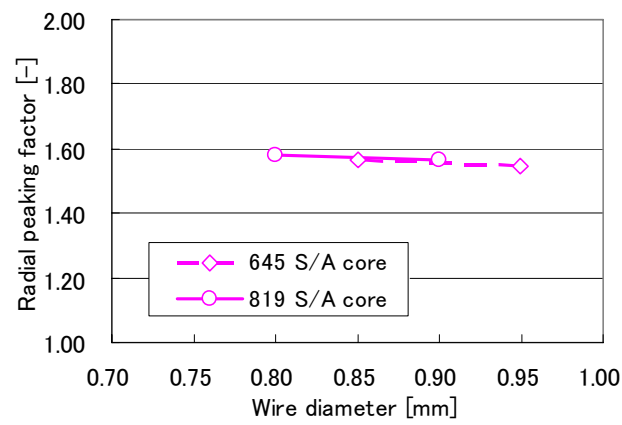

(d) Radial peaking factor

Figure 4 Effect of wire diameter upon core characteristics 
The radial peaking factor is independent on the subassembly number. It means the peak bundle power decreases with the subassembly number. Therefore, the bundle pressure drop also decreases. The bundle pressure drop of the 819 subassembly core with $0.90 \mathrm{~mm}$-diameter wire is $0.36 \mathrm{MPa}$.

Because there is a margin in the bundle pressure drop of the 819 subassembly core with $0.90 \mathrm{~mm}$-diameter wire, we considered to apply the smaller diameter wire and to reduce the subassembly number. From Fig. 4 (c), the bundle pressure drop of 819 subassembly core is expected to be $0.4 \mathrm{MPa}$ with $0.85 \mathrm{~mm}$-diameter wire. In order to find the minimum subassembly number to satisfy the bundle pressure drop condition efficiently, dependence of the bundle pressure drop upon the subassembly number was roughly estimated as shown in Fig. 5. From the figure, it is found that the bundle pressure drop is $0.4 \mathrm{MPa}$ as the subassembly number is approximately 770 .

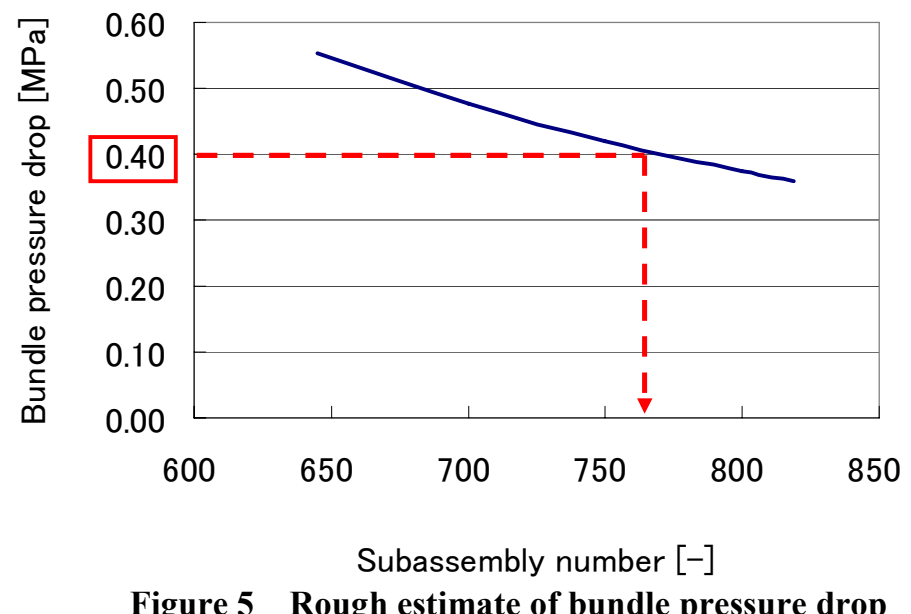

Table 3 lists the characteristics of these candidates. The breeding ratio of the 765 subassembly core with $0.90 \mathrm{~mm}$-diameter wire is nearly equal to that of 819 subassembly core with $0.85 \mathrm{~mm}$-diameter wire core; however, the Pu-fissile inventory of 765 subassembly core is $5 \%$ smaller. Therefore, the 765 subassembly core was found to be the best high breeding ratio core.

Table 3 Comparison of characteristics between candidates of high breeding ratio cores

\begin{tabular}{|l|c|c|c|}
\hline \multicolumn{1}{|c|}{ Item } & Unit & $\begin{array}{c}\text { Applying } 0.85 \mathrm{~mm} \\
\text { diameter wire }\end{array}$ & $\begin{array}{c}\text { Reduction of S/A } \\
\text { number }\end{array}$ \\
\hline Number of S.A. & - & 819 & 765 \\
\hline Wire diameter & $\mathrm{mm}$ & 0.85 & 0.90 \\
\hline Refueling batch & - & \multicolumn{2}{|c|}{3} \\
\hline Breeding ratio & - & 1.33 & 1.32 \\
\hline Discharge burnup & $\mathrm{GWd} / \mathrm{t}$ & 65.9 & 66.4 \\
\hline Burnup reactivity & $\% \Delta \mathrm{k} / \mathrm{kk}$ & -4.9 & -4.8 \\
\hline Pu-f inventory & $\mathrm{t} / \mathrm{GWe}$ & 8.4 & 7.9 \\
\hline Core equivalent diameter & $\mathrm{m}$ & 5.8 & 5.6 \\
\hline Sodium void worth & $\$$ & 7.7 & 7.9 \\
\hline Core outlet temperature & ${ }^{\circ} \mathrm{C}$ & 516 & 516 \\
\hline Bundle pressure drop & $\mathrm{MPa}$ & 0.40 & 0.40 \\
\hline
\end{tabular}




\subsection{Effect of Refueling Batch}

In the previous section, the 765 subassembly core was selected as the best of the high breeding ratio core. Because the absolute value of the burnup reactivity is large, it should be improved by an increase of refueling batch. The power swing was expected to decrease and the core outlet temperature was expected to increase.

Figure 6 shows the effect of the refueling batch. In the survey shown in Fig. 6(a) (e), the major core specifications were fixed except for the refueling batch and the operation cycle length. The subassembly number ratio between the inner and the outer cores was adjusted in Fig. 6 (f).

By an increase of the refueling batch from 3 to 6 , the breeding ratio increases from 1.32 to 1.35. Although the void worth is slightly increased, the void worth condition is satisfied. By the increase of the refueling batch, the absolute value of the burnup reactivity is reduced. The core outlet temperature increases from $516{ }^{\circ} \mathrm{C}$ to $520{ }^{\circ} \mathrm{C}$; however, the bundle pressure drop also increases. Hence, it was necessary to adjust the subassembly number ratio in order to satisfy the bundle pressure drop condition. Figure 6(f) shows dependence of the bundle pressure drop, it was found that the bundle pressure drop condition is satisfied as the subassembly number ratio is 0.46 . The breeding ratio of the adjusted core was 1.34, the Pu-fissile inventory $7.6 \mathrm{t} / \mathrm{GWe}$, and the core outlet coolant temperature $519^{\circ} \mathrm{C}$. Thus, this was selected as the resultant high breeding ratio core with 6 $\mathrm{wt} \% \mathrm{Zr}$-content fuel. Figure 7 shows $\mathrm{R}-\mathrm{Z}$ model of the resultant high breeding ratio core.

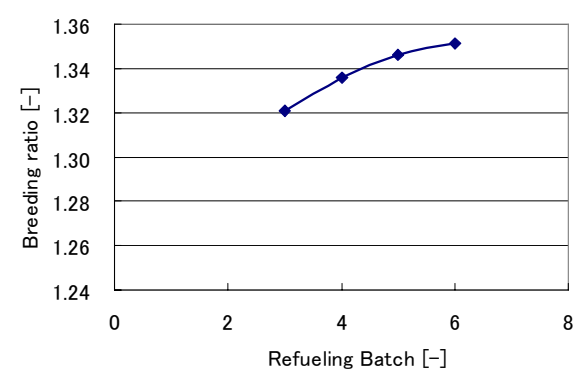

(a) Breeding ratio

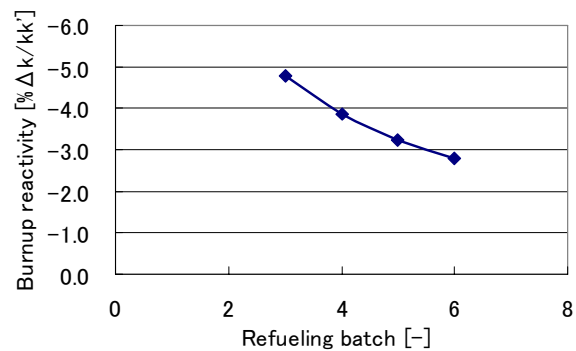

(c) Burnup reactivity

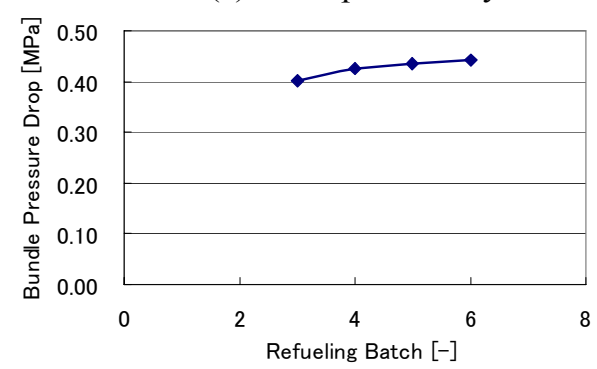

(e) Bundle pressure drop

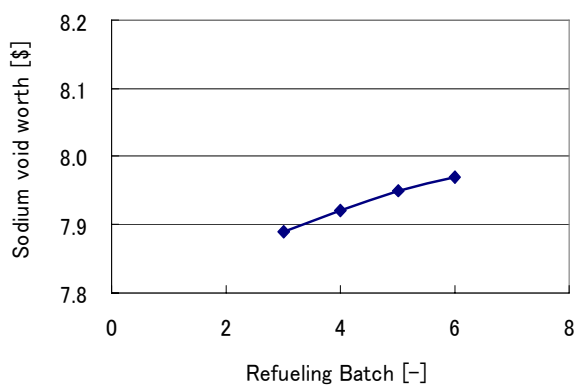

(b) Void worth

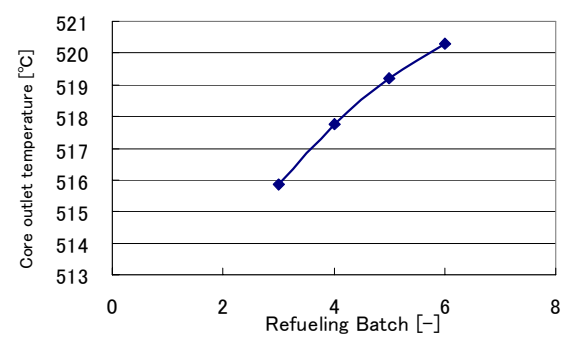

(d) Core outlet temperature

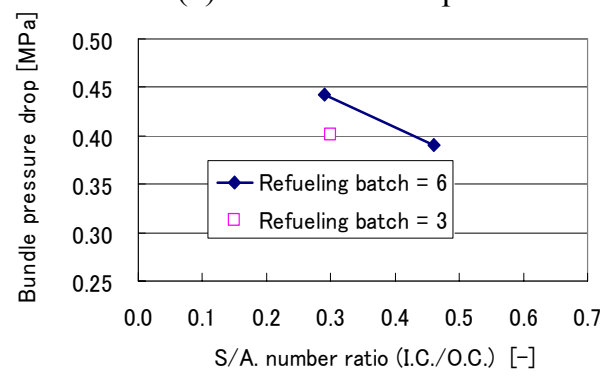

(f) Adjustment of S/A number ratio

Figure 6 Effect of Refueling batch upon core characteristics 


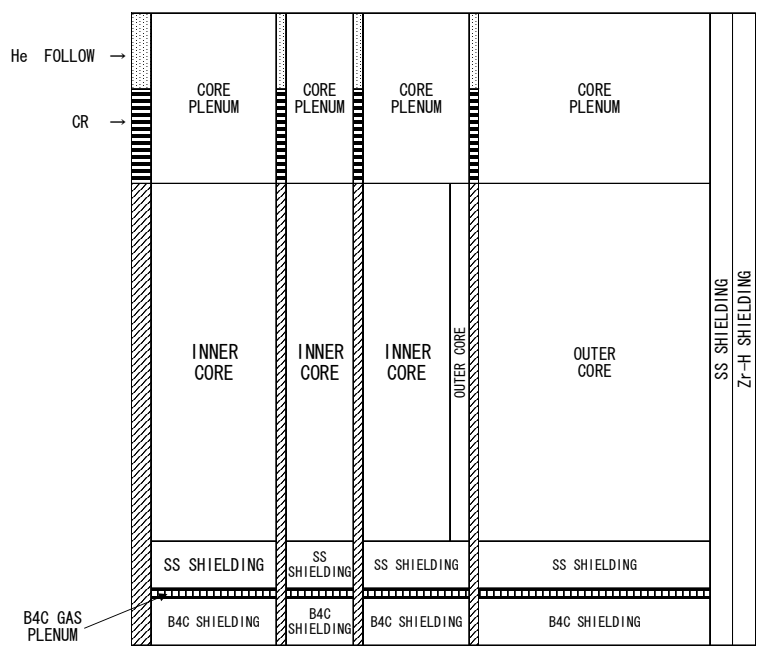

Figure $7 \quad \mathrm{R}-\mathrm{Z}$ model of the resultant high breeding ratio core

\subsection{Specifications of High Breeding Ratio Core}

Table 4 shows the major specifications and the characteristics of the resultant high breeding ratio core without blanket fuels. In the table, those of the core adopting $3 \mathrm{wt} \%$ $\mathrm{Zr}$-content fuel are also listed. The specifications of the $3 \mathrm{wt} \% \mathrm{Zr}$-content fuel core are obtained by replacing the fuel $\mathrm{Zr}$-content from $6 \mathrm{wt} \%$ to $3 \mathrm{wt} \%$ and by adjusting the subassembly number ratio between the inner and outer cores for satisfying the bundle pressure drop conditions.

By adopting the $3 \mathrm{wt} \% \mathrm{Zr}$-content fuel, the breeding ratio is enhanced up to 1.40 . It is because the Pu-enrichment of the $3 \mathrm{wt} \% \mathrm{Zr}$-content fuel is lower than that of the $6 \mathrm{wt} \%$ $\mathrm{Zr}$-content fuel due to its higher heavy metal densities. Although the Pu-enrichment of the $3 \mathrm{wt} \% \mathrm{Zr}$-content fuel core is lower, the Pu-f inventory is almost the same as that of the $6 \mathrm{wt} \% \mathrm{Zr}$-content fuel core. It is because the higher heavy metal densities of the $3 \mathrm{wt} \%$ $\mathrm{Zr}$-content fuel.

Although the $\mathrm{Pu}$-enrichment 1-region core may satisfy the design conditions by adopting $3 \mathrm{wt} \% \mathrm{Zr}$-content fuel, the $\mathrm{Zr}$-content of the inner core must be larger than $3 \mathrm{wt} \%$. Therefore, the Pu-enrichment 1-region core adopting 3wt\% $\mathrm{Zr}$-content fuel is not expected better than the Pu-enrichment 2-region core in the right hand side column in Table 4.

Table 4 Major specifications and characteristics of high breeding ratio cores

\begin{tabular}{|c|c|c|c|}
\hline \multirow{2}{*}{ Item } & \multirow{2}{*}{ Unit } & \multicolumn{2}{|c|}{ Highest breeding ratio core } \\
\hline & & $6 \mathrm{wt} \% \mathrm{Zr}$-content fuel & $3 w t \% \mathrm{Zr}$-content fuel \\
\hline Fuel $\mathrm{Zr}$-content (IC/OC) & wt $\%$ & $6.0 / 6.0$ & $3.0 / 3.0$ \\
\hline Fuel Pin Outer Diameter & $\mathrm{mm}$ & \multicolumn{2}{|c|}{8.5} \\
\hline Spacer Wire Diameter & $\mathrm{mm}$ & \multicolumn{2}{|c|}{0.90} \\
\hline Core Hight & $\mathrm{cm}$ & \multicolumn{2}{|c|}{150} \\
\hline S.A. Number ( IC/OC/total) & - & $240 / 525 / 765$ & $276 / 489 / 765$ \\
\hline Refueling Batch & - & \multicolumn{2}{|c|}{6} \\
\hline Core Thermal Output & MWth & \multicolumn{2}{|c|}{3530} \\
\hline Operation Cycle Length & days & 650 & 680 \\
\hline Fuel $\mathrm{Pu}$-enrichement (IC/OC) & wt $\%$ & $7.4 / 8.3$ & $6.9 / 7.6$ \\
\hline Breeding Ratio & - & 1.34 & 1.40 \\
\hline Burnup Reactivity & $\% \Delta \mathrm{k} / \mathrm{kk}$ & -2.8 & -3.3 \\
\hline Discharge Burnup & $\mathrm{GWd} / \mathrm{t}$ & 68.5 & 65.7 \\
\hline Pu-fissile Inventory & $\mathrm{t} / \mathrm{GWe}$ & 7.6 & 7.6 \\
\hline Sodium Void Worth & $\$$ & 8.0 & 7.6 \\
\hline Core Outlet Temperature & ${ }^{\circ} \mathrm{C}$ & 519 & 515 \\
\hline Bundle Pressure Drop & $\mathrm{MPa}$ & 0.39 & 0.39 \\
\hline Hoop Stress & $\mathrm{MPa}$ & 112 & 112 \\
\hline
\end{tabular}




\section{Conclusion}

An attractive metal fuel core concept of high breeding ratio core without blankets was established taking into consideration of thermal-hydraulic and fuel integrity conditions. In order to pursue for the breeding capability of the metal fuel core, the design conditions were flexibly set on the basis of the recent fuel irradiation test results.

In order to satisfy the conditions on the bundle pressure drop of $<0.4 \mathrm{MPa}$ and the void worth of $<8 \$$, the Pu-enrichment 2-region core was more adopted than the Pu-enrichment 1-region core. The 765 subassembly core with $0.90 \mathrm{~mm}$-diameter wire was selected as the high breeding ratio core design with the $\mathrm{Zr}$-content $6 \mathrm{wt} \%$ fuel. Its breeding ratio was 1.34. By adopting $3 \mathrm{wt} \% \mathrm{Zr}$-content fuels, the breeding ratio was enhanced up to 1.40 .

\section{Acknowledgement}

The authors deeply appreciate the cooperation of Mr. H. Komoda of NESI Ltd.

\section{References}

(1) Sugino, K, Ogawa, T., Okano, Y., and Mizuno, T., Advanced Metal Fuel Core Design Study for SFR in the "Feasibility Study" in Japan, Proceedings of Int. Conf. Global 2005, (2005), CD-ROM, \#399.

(2) Ogawa, T., Kobayashi, N., Naganuma, M., Ohki, S., and Mizuno, T., A Design Study of the Sodium Cooled Metal Fuel Core with High Reactor Outlet Temperature Aiming for the Enhancement of Safety, 2007 Fall Meeting of Atomic Energy Society of Japan, (2007), D36, (in Japanese).

(3) Niwa, H., Aoto, K., and Morishita, M., Current status and perspective of advanced loop type fast reactor in fast reactor cycle technology development project, Proceedings of Int. Conf. Global 2007, (2007), pp. 62-70.

(4) Riyas, A. and Mohanakrishnan, P., Studies on physics parameters of metal (U-Pu-Zr) fuelled FBR cores, Annals of Nuclear Energy, Vol. 35, (2008), pp. 87-92.

(5) Dubberley, A.E., Yoshida, K., Boardman, C.E., and Wu, T., Superprism oxide and metal fuel core designs, Proceedings of $8^{\text {th }}$ International Conference on Nuclear Engineering, (2000), CD-ROM, \#8002.

(6) Tsai, H., and Neimark, L.A., Irradiation Performance of Full-Length Metallic IFR Fuels, Proceedings of Int. Conf. on Design and Safety of Advanced Nuclear Power Plants, (1992) , \#28.2-1.

(7) Crawford, D. C., Lahm, C.E., Tsai, H., and Pahl, R.G., Performane of U-Pu-Zr Fuel Cast into Zirconium Molds, J. Nucl. Mater. Vol. 204, (1993), pp.157-164.

(8) Cheng, S.K., and Todreas, N.E., Hydrodynamic Models and Correlations for Bare and Wire-Wrapped Hexagonal Rod Bundles - Bundle Friction Factors, Subchannel Friction Factors and Mixing Parameters, Nuclear Engineering and Design, Vol.92, (1986), pp.227-251. 